\title{
Scenarios in the development of Mediterranean cyclones
}

\author{
M. Romem ${ }^{1}$, B. Ziv ${ }^{2}$, and H. Saaroni ${ }^{1}$ \\ ${ }^{1}$ Department of Geography and the Human Environment, Tel Aviv University, 69978, Israel \\ ${ }^{2}$ The Open University of Israel, P.O.B. 808 Raanana, 43107, Israel
}

Received: 11 March 2007 - Accepted: 19 June 2007 - Published: 5 July 2007

\begin{abstract}
The Mediterranean is one of the most cyclogenetic regions in the world. The cyclones are concentrated along its northern coasts and their tracks are oriented more or less west-east, with several secondary tracks connecting them to Europe and to North Africa. The aim of this study is to examine scenarios in the development of Mediterranean cyclones, based on five selected winter seasons (OctoberMarch). We detected the cyclones subjectively using 6hourly Sea-Level Pressure maps, based on the NCAR/NCEP reanalysis archive.
\end{abstract}

HMSO (1962) has shown that most Mediterranean cyclones (58\%) enter the Mediterranean from the Atlantic Ocean (through Biscay and Gibraltar), and from the southwest, the Sahara Desert, while the rest are formed in the Mediterranean Basin itself. Our study revealed that only $13 \%$ of the cyclones entered the Mediterranean, while $87 \%$ were generated in the Mediterranean Basin. The entering cyclones originate in three different regions: the Sahara Desert (6\%), the Atlantic Ocean (4\%), and Western Europe (3\%).

The cyclones formed within the Mediterranean Basin were found to generate under the influence of external cyclonic systems, i.e. as "daughter cyclones" to "parent cyclones" or troughs. These parent systems are located in three regions: Europe (61\%), North Africa and the Red Sea (34.5\%) and the Mediterranean Basin itself (4.5\%). The study presents scenarios in the development of Mediterranean cyclones during the winter season, emphasizing the cyclogenesis under the influence of various external forcing.

The large difference with respect to the findings of HMSO (1962) is partly explained by the dominance of spring cyclones generating in the Sahara Desert, especially in April and May that were not included in our study period.

Correspondence to: $\mathrm{H}$. Saaroni

(saaroni@post.tau.ac.il)

\section{Background}

The Mediterranean Basin (MB) is one of the most cyclogenetic regions in the world (Petterssen, 1956; HMSO, 1962; Campins et al., 2000). This is in spite of its being south of the global mid-latitude cyclone belt and the fact that its southern end, latitude $30^{\circ} \mathrm{N}$, denotes the northern border of the global desert belt (Trewartha and Horn, 1980; Ahrens, 2000). The southern location of the MB suppresses cyclonic activity in the summer, leaving the winter as the main active season. In the winter, the MB offers all the cyclogenetic factors, being highly baroclinic, warmer than its surroundings and positioned at the lee of mountain ridges, such as the Atlas ridge in Morocco, the European Alps and the Taurus ridge in Turkey (HMSO, 1962; Alpert et al., 1990, 1996; Trigo et al., 1999; Lionello et al., 2006).

The MB winter cyclones have some special characteristics: they develop mainly at the northern Mediterranean coasts; their horizontal size varies between meso-scale and synoptic-scale (Alpert et al., 1990; Trigo et al., 1999; Campins et al., 2000; Trigo, 2006; Lionello et al., 2006); their life span is around one to four days; their typical speed is $\sim 5 \mathrm{~ms}^{-1}$; they reach the troposphere (Alpert and Ziv, 1989). In addition to the winter cyclones, another type of frontal cyclone, known as the "Sharav", or "North African Cyclone" (Alpert and Ziv, 1989), is observed in the MB. These cyclones, most frequent in the spring season, develop and move along the southern coast of the MB. They owe their existence to the high temperature gradient that develops between the Mediterranean Sea and the African continent during that season (Alpert and Ziv, 1989).

The winter cyclone track in the MB co-exists with the $\mathrm{Eu}-$ ropean track, which is an extension of the Atlantic stormtrack. It is therefore possible that the MB cyclones are influenced by the European ones (HMSO, 1962; Alpert et al., 1990; Lionello et al., 2006).

Published by Copernicus Publications on behalf of the European Geosciences Union. 


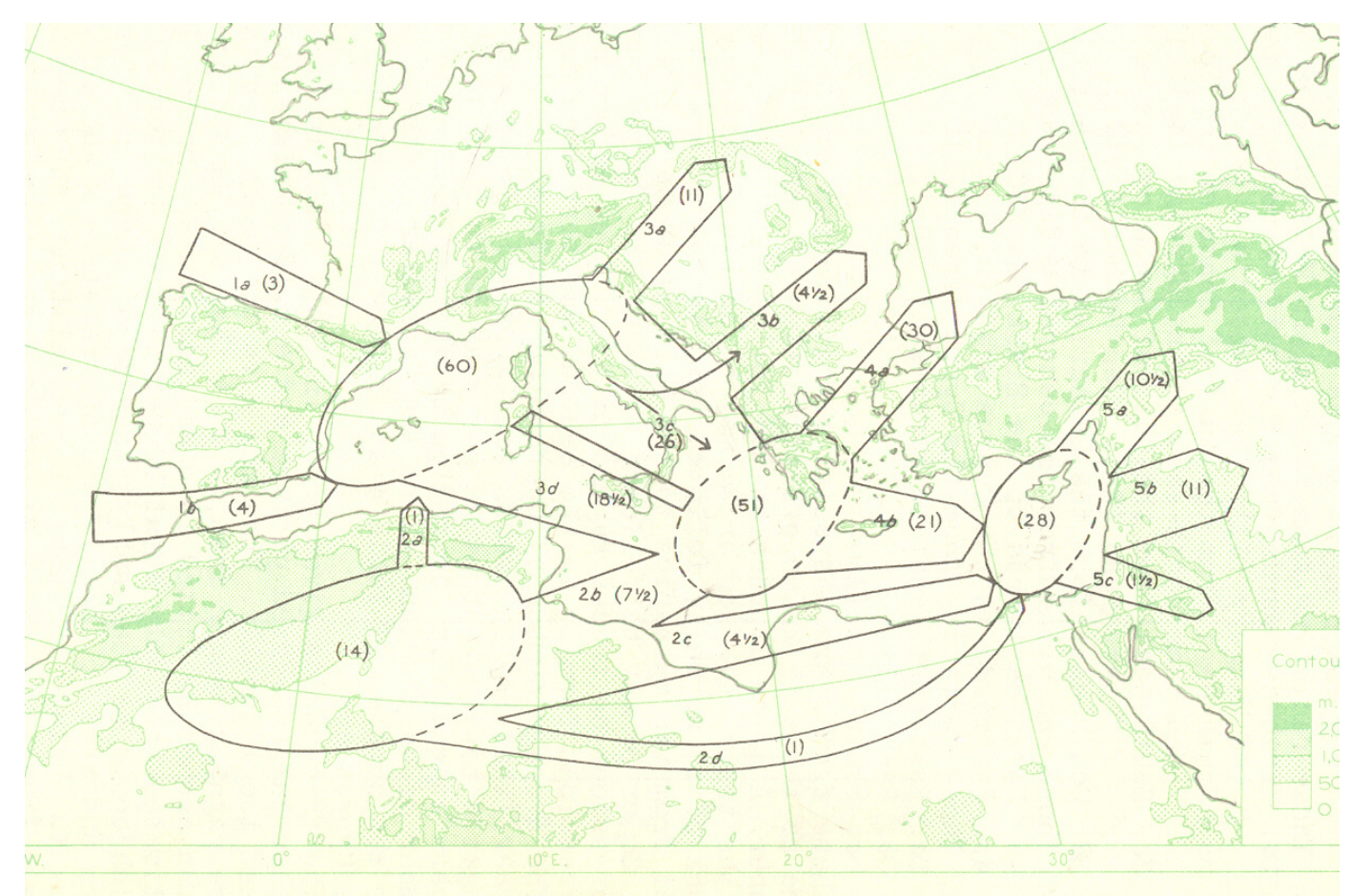

Fig. 1. Main winter cyclone track in the MB. Average annual frequencies are shown in brackets (HMSO, 1962, p. 33).

HMSO (1962) documented the cyclone tracks in the MB, see Fig. 1. The main track is eastward, along the northern coast of the Mediterranean, down to the Levant region, with three branches toward the northeast, where cyclones leave the MB in favor of the European track; two in the Adriatic Sea and one in the Aegean Sea. An additional track extends from the lee of the Atlas along the North Africa coast.

HMSO (1962) differentiated between cyclones that have formed within the MB and those entering that region. They found that $42 \%$ of the MB cyclones are formed outside the Basin. They divided the MB into three parts and emphasized the western MB as the most cyclogenetic. Other studies also described the typical track that starts from the western part of the MB and moves along it down to its eastern end.

Many efforts have been made to map the MB cyclogenetic regions (Petterssen, 1956; Alpert et al., 1990; Trigo et al., 1999; Campins et al., 2000; Maheras et al., 2001; Genovés et al., 2006; Lionello et al., 2006; Trigo, 2006). The main regions are: the Gulf of Genoa, the Iberian Peninsula, Palos, the Atlantic coast of Morocco, southern Italy, the Aegean Sea, the Tyrrhenian Sea, south of Sardinia, the Ionic sea, the Balares Islands and Cyprus.

Reiter (1975) mentions that the most cyclogenetic region is the western MB, but Alpert et al. (1990) and Petterssen (1956) found that the eastern MB is more cyclogenetic than the western part (the Gulf of Genoa)

The present study attempts to re-evaluate those cyclones formed in the MB and those entering the region. In addition, a special effort is devoted to identifying and outlining the main scenarios of Mediterranean cyclogenesis. The motivation for this study is improvement of the atmospheric data base. Here, we present preliminary results, based on five winter seasons. Section 2 specifies the data and methodology used, Sect. 3 describes the results and Sect. 4 summarizes the implications of our findings and outlines the next stages for the research.

\section{Methodology and data base}

Five winter seasons (October-March) were selected: 1986/7, $1991 / 2,2001 / 2,2002 / 3,2003 / 4$. These winters were selected as representing different types of cyclone formation. For instance in 1991/2 the cyclones were continuously concentrated in the eastern Mediterranean, whereas in 1986/7 there was a considerable shift in their location during the season. We chose the period October-March as the winter season since it is the period when most MB cyclones affect the region (HMSO, 1962).

The database is the sea-level pressure (SLP) maps taken from the NCEP/NCAR CDAS-1 archive (Kalnay et al., 1996; Kistler et al., 2001) reanalysis gridded data, with a $2.5^{\circ} \times 2.5^{\circ}$ spatial and $6 \mathrm{~h}$ temporal resolutions. The study region covers the domain $25^{\circ} \mathrm{N}-65^{\circ} \mathrm{N}$ and $20^{\circ} \mathrm{W}-45^{\circ} \mathrm{E}$.

The 6 hourly SLP maps were scanned subjectively and the center of each cyclone was detected and marked. Since eastern MB cyclones are characterized by a relatively high 
pressure, we avoided using any threshold for the central pressure of cyclones or for the pressure gradient

\section{Results}

\subsection{The origins of entering cyclones}

For the five studied seasons, only $13 \%$ of the observed cyclones were generated outside the MB, and these were found to enter the region along three different routes (Fig. 2). The largest number of entering cyclones $(46 \%)$ originated from the Sahara Desert, at the lee of the Atlas Mountains (as described in detail by Egger et al. (1995) and seen in Fig. 2a). Some of these cyclones were found to move along the North African coast, others along the Mediterranean Sea, in agreement with HMSO (1962) and Alpert and Ziv (1989). 43\% of them reached the eastern coast of the MB.

The second area of origin for Mediterranean cyclones is the Atlantic Ocean $(31 \%)$. These cyclones entered the MB through Gibraltar and Biscay (Fig. 2b) and continued their track eastward, mostly along the northern coast of the Mediterranean Sea. Most of them (88\%) turned northeastward at the Aegean Sea and reached the Black Sea. The rest (12\%) proceeded eastward and reached the eastern coast of the MB.

The third area of origin is Western Europe (23\%), mostly through the Gulf of Genoa (Fig. 2c). This scenario was not noted by HMSO (1962). The cyclones moved eastward and turned northeastward where some of them merged with the European cyclone track. It was found that only one reached the eastern coast of the Mediterranean

It should be noted that while most cyclones originating from the Sahara Desert reached the eastern coast of the MB, only a minority of the cyclones originating in the Atlantic reached that region and almost none of those originated in Western Europe.

3.2 Scenarios of cyclogenesis within the Mediterranean Basin

Our study revealed that most cyclones, $87 \%$, were generated in the MB itself. This cyclogenesis was found to form under the influence of a pre-existing cyclonic system, defined as a "parent cyclone". The scenarios described below concentrate on the location of the genesis in the MB with respect to the location of the "parent cyclone", being either in Europe, North Africa or the MB itself.

\subsubsection{European "parent cyclones"}

Most (61\%) of the cyclones generating in the MB are formed as "daughter cyclones" by the influence of European "parent cyclones". The cyclogenesis occurred in the lee of the main mountain ridges, i.e., the Alps (e.g., Egger 1998), the Balkans or the Taurus. Three scenarios were identified (as
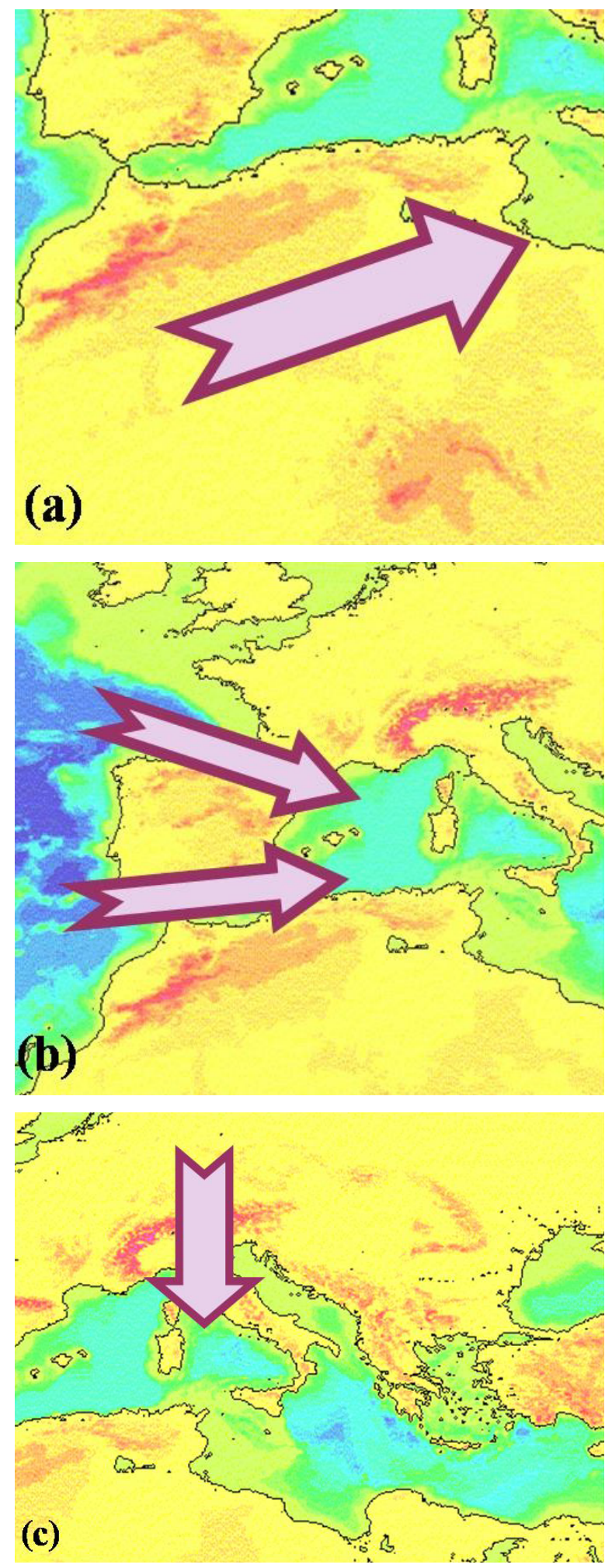

Fig. 2. Main scenarios of entering cyclones: (a) The Sahara Desert (b) The Atlantic Ocean and (c) Western Europe. 

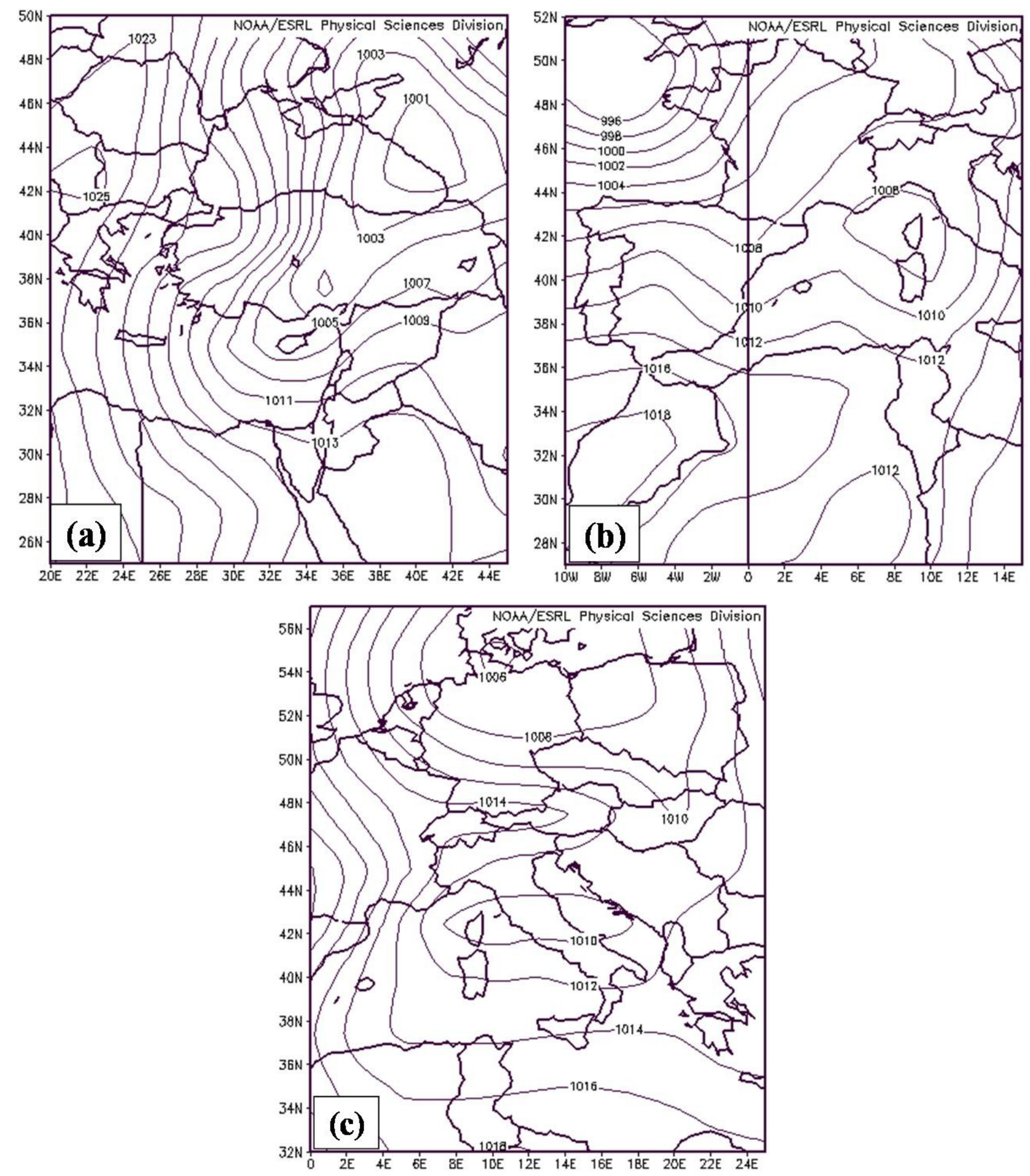

Fig. 3. Sea level pressure for cyclones generated as "daughter cyclones" by the influence of European "parent cyclones": (a) East Europe (14 February 2004 00:00 UTC) (b) West Europe (12 October 1991 00:00 UTC) and (c) central Europe (23 January 2003 06:00 UTC).

illustrated in Fig. 3). In the first scenario (51\% of the cases related to European cyclones), the parent cyclones were lo- cated over Eastern Europe and the resulting cyclogenesis took place over the Aegean Sea and or the lee of the Taurus 

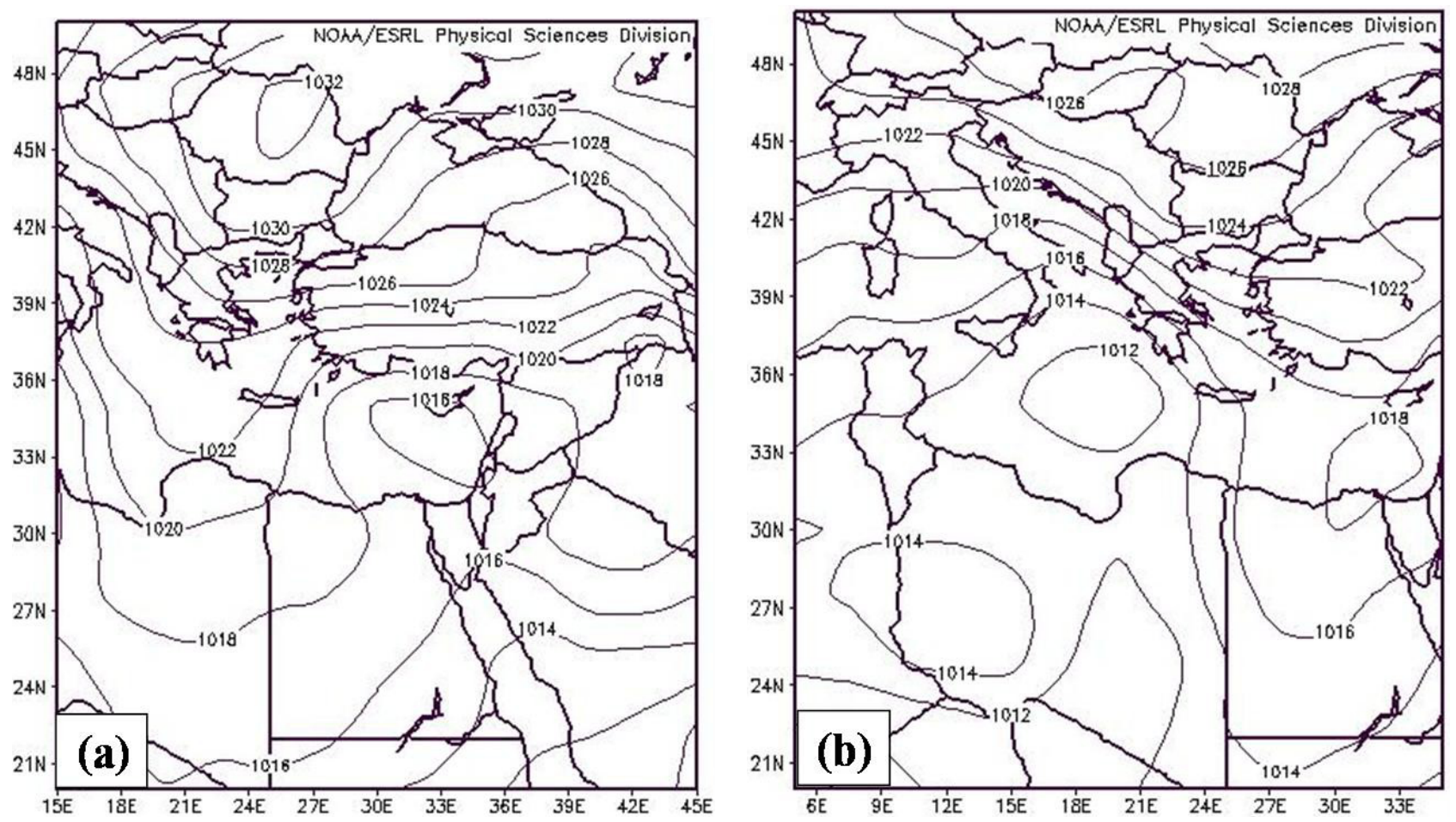

Fig. 4. Sea level pressure for cyclones generated within easterly African troughs: (a) East MB (3 December 2003 18:00 UTC), (b) central MB (10 February 2003 18:00 UTC).

Mountains. All of these cyclones reached the eastern part of the MB and then moved further to the east or turned north, at southeast Turkey, toward the Black Sea (Fig. 3a). In some cases the "daughter" Mediterranean cyclone, when reaching the Black Sea, generated another cyclone in the eastern Mediterranean that can be referred as a "granddaughter cyclone".

In the second scenario $(25.5 \%)$, the cyclones were generated over the western part of the MB, mostly in the Gulf of Genoa or the lee of the Pyrenees, under the influence of Atlantic cyclones, which became European cyclones (Fig. 3b). These cyclones moved eastward and when reaching Italy or the Aegean Sea turned northward and merged with the European cyclone track. Only $10 \%$ of those cyclones reached the eastern MB.

In the third scenario $(23.5 \%)$, the cyclones were generated at the central MB, mostly south of the Italian Alps. The "parent" cyclones were located over central Europe, almost precisely north of the region of the Mediterranean cyclogenesis (Fig. 3c). 10.7\% of those cyclones reached the eastern MB.

To conclude, the location of the "parent" cyclone with respect to the MB, determines the location of the cyclogenesis, and the tracks of the "daughter" cyclone. Generally, for parent cyclones located over Western Europe, the cyclogenesis took place southeast of it. For central Europe, it took place to the south, and for Eastern Europe the cyclogenesis took place to the southwest. After their formation, the "daughter" cyclones move mostly eastward; some of them reach the Eastern MB, some of them dissipate in the central MB and the rest merge with the European cyclone track. The further the cyclogenesis was from the Eastern MB, the smaller was the chance of the "daughter" cyclone reaching that region.

\subsubsection{Genesis within easterly trough over North Africa}

The MB was frequently found to be dominated by an easterly flow associated with a north-south pressure gradient. Under these circumstances troughs extended from Africa, within which cyclones develop over the southern coasts of the Mediterranean. Such a development, which can be considered as reflecting transformation of tropical disturbances to extratropical cyclones, was observed in both the western, central and eastern parts of the MB. This scenario was responsible for $34.5 \%$ of the cyclones generated in the MB (Fig. 4).

Two preferred locations for this type of cyclogenesis were identified. The first $(68.5 \%$ of the cases) is the eastern part of the MB, mostly in the vicinity of Crete. An example of such a development is the so-called Red Sea trough, within which a cyclone is formed near Cyprus (e.g., Dayan et al., 2001 and Fig. 4a). These cyclones move eastward toward the eastern coast of the Mediterranean or turn northward, down 


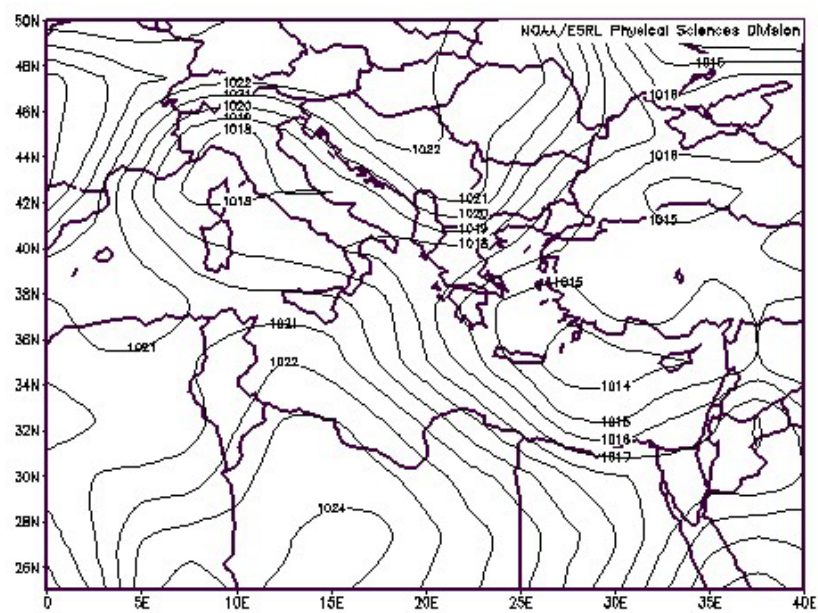

Fig. 5. Sea level pressure for 6 November 2001 00:00 UTC, when a cyclone was formed under the influence of a Mediterranean "parent cyclone".

to the Black Sea. The second $(31.5 \%$ of the cases) is the western and the central parts of the MB, Sardinia, Sicily and north Libya. In most cases, these cyclones moved eastward along the southern coasts of the Mediterranean, and reached its eastern coast (Fig. 4b). The trough within which these cyclones were formed in the western part of the Mediterranean was oriented mostly southwest-northeast (Fig. 4b), but for those which developed in the eastern MB the orientation of the trough is south-north.

\subsubsection{Cyclogenesis induced by Mediterranean "parent cy- clones"}

Several cyclones were found to be generated by a "parent cyclone" which was itself a Mediterranean cyclone (Fig. 5). This scenario includes only $4.5 \%$ of the cyclones generated in the MB.

It occurs when a Mediterranean cyclone reaches the eastern part of the MB and develops a trough to its west, toward the central part of the Mediterranean. In this trough, a "daughter cyclone" develops, mostly next to the Italian peninsula. The "daughter cyclone" tends to move eastward either to the eastern MB or northward reaching the coast of southern Turkey.

\section{Summary and discussion}

Figure 6 summarizes the scenarios found for the development of Mediterranean cyclones. The thick arrows represent the routes through which cyclones enter the MB. The solid arrows represent the main locations of the cyclones or troughs within which cyclogenesis occurs, defined as "parent cyclones".

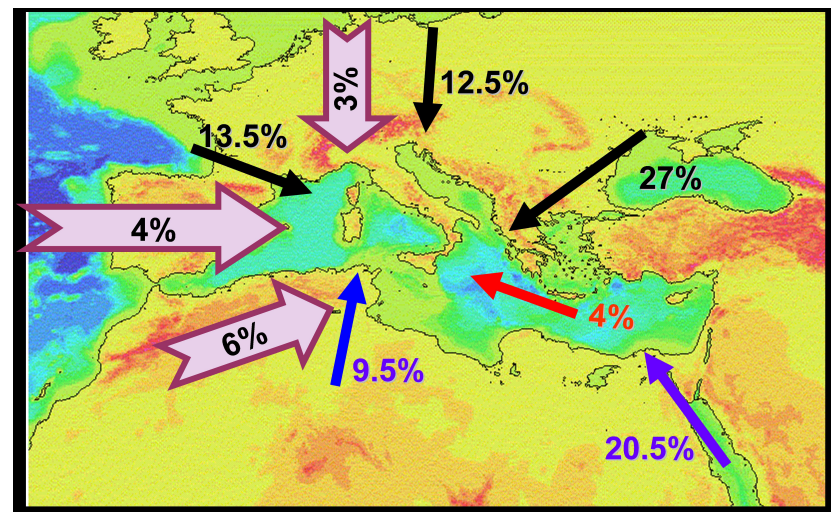

Fig. 6. Summary of the scenarios for the development of cyclones in the Mediterranean Basin. Thick violet arrows represent tracks of cyclones entering the MB and solid arrows represent the troughs within which cyclogenesis takes place.

The vast majority $(87 \%)$ of the cyclones are generated inside the MB. This percentage is more than twice the $42 \%$ reported by HMSO (1962). The difference may be partly explained by our choice to focus on the winter season (October-March), and to exclude April and May, known to be the peak of the Sahara originated cyclones.

The Mediterranean cyclogenesis was found to be induced by the influence of external cyclonic systems. This includes Atlantic cyclones, European cyclones, widespread low pressure systems over Africa and even pre-existing Mediterranean cyclones. The main contributors were "parent cyclones" located over Europe, especially over Eastern Europe (which generated $\sim 1 / 4$ of the Mediterranean cyclones). Another important source of Mediterranean cyclogenesis is the Red Sea Trough ( $\sim 1 / 5$ of the Mediterranean cyclones).

The cyclogenesis, induced by European or Mediterranean cyclones, took place at the lee of the main mountain ridges, mainly the Alps, the Balkans and the Taurus. The location of the "parent cyclones" with respect to the MB determined the relative location and track of the "daughter cyclone" formed. When the parent cyclone is located in the western, central or eastern Europe the cyclogenesis takes place southeast, south and southwest respectively of the "parent cyclone".

After being generated, the "daughter cyclones" move mostly eastward. Some of them reach the Eastern MB, some of them dissipate in the central MB and the rest merge with the European cyclone track. The further the cyclogenesis from the Eastern MB, the less the chance of the "daughter cyclone" of reaching that region. Our findings stress the fact that MB cyclones that are formed in the western Mediterranean, or entering there, do not always move along the entire MB down to its eastern end. Only a few cyclones (10.3\%), succeed in reaching this endpoint and the rest turn northeastward at the Aegean Sea or southern Turkey.

This preliminary study has found, according to the frequencies of cyclones, that the eastern $\mathrm{MB}$ is a more 
cyclogenetic region than the western part (Gulf of Genoa), c.f. Alpert et al. (1990) and Petterssen (1956).

The cyclogenesis induced by easterly waves can be considered as tropical-extratropical interaction, i.e., a transition of tropical disturbance into an extra-tropical cyclone (as found by Ziv (2001) when a tropical surface trough, developed under a tropical plume, generated a Mediterranean active cyclone). However, not all of the easterly troughs are real tropical disturbances, since a newly formed cyclone, while superimposed on a pre-existing south-north pressure gradient, also resembles an easterly trough. Of course, after further deepening, the forming cyclone becomes visible as a closed cyclone.

Another finding regarding the development of MB cyclones is that in several cases the cyclogenesis took place in sequence. For instance, a Mediterranean cyclone that moved northeast, and became a European cyclone, formed a new Mediterranean cyclone (which can be entitled a "granddaughter cyclone") and so on (e.g., on 12-14 February 2004, in the eastern Mediterranean, not shown).

It should be emphasized that this research is a preliminary study examining only five seasons. We believe that extending the study period to 50 years will authenticate the scenarios found here. Moreover, an objective methodology for analyzing cyclones and their development is being developed in order to expose the inter-relations between the European and the Mediterranean cyclones objectively as well as the detailed development of MB cyclones within easterly troughs. Since most of these cyclones are baroclinic, a more complete research study is needed to investigate the 3-D structure of these cyclones for the various scenarios.

Acknowledgement. This study was supported by the Israeli Science Foundation (ISF, grant no. 764/06).

Edited by: P. Alpert, H. Saaroni, and E. Heifetz

Reviewed by: two anonymous referees

\section{References}

Ahrens, C. D: Meteorology Today - an Introduction to Weather, Climate and Environment, 6th edition, 2000.

Alpert, P. and Ziv, B.: The Sharav cyclone: observation and some theoretical considerations, J. Geoghys. Res., 94, 18 495-18 514, 1989.

Alpert, P., Neeman, B. U., and Shay-El, Y.: Climatological Analysis of Mediterranean Cyclones Using ECMWF Data, Tellus, 42A, 65-77, 1990.

Alpert, P., Tzidulko, M., Krichak, S., and Stein, U.: A multi-stage evolution of an ALPEX cyclone, Tellus, 48A, 209-222, 1996.
Campins, J., Genoves, A., Jansa, A., Guijarro, J. A., and Ramis, C.: A Catalogue and a Classification of Surface Cyclones for the Western Mediterranean, Int. J. Climatol., 20, 969-984, 2000.

Dayan, U., Ziv, B., Margalit, A., Morin, E., and Sharon, D.: A Severe Autumn Storm Over the Middle-East: Synoptic and Mesoscale Convection, Theor. Appl. Climatol., 69, 103-122, 2001.

Egger, J.: Alpine lee Cyclogenesis: Verification of Theories, J. Atmos. Sci., 45, 2187-2203, 1998.

Egger, J., Taferner, A., Alpert, P., and Ziv, B.: Numerical experiments on the genesis of Sharav cyclones, Tellus, 47A, 162-174, 1995.

Genovés, A., Campins, J., and Jansà, A.: Intense Storms in the Mediterranean: A First Description from the ERA-40 Perspective, Adv. Geosci., 7, 163-168, 2006, http://www.adv-geosci.net/7/163/2006/.

HMSO: Weather in the Mediterranean I: General Meteorology, 2d ed., Her Majesty's Stationery Office, 362 p., 1962.

Kalnay, E., Kanamitsu, M., Kistler, R., Collins, W., Deaven, D., Gandin, L., Iredell, M., Saha, S., White, G., Woollen, J., Zhu Y Chelliah, M., Ebisuzaki, W., Higgins, W., Janowiak, J., Mo, K. C., Ropelewski, C., Wang, J., Leetmaa, A., Reynolds, R., Jenne, R., and Joseph, D.: The NCEP/NCAR 40-Year Reanalysis Project, B. Am. Meteorol. Soc., 77, 437-471, 1996.

Kistler, R. E., Kalnay, W., Collins, S., Saha, G., White, J., Woollen, M., Chelliah, W., Ebisuzaki, M., Kanamitsu, V., Kousky, H., Dool, V. D., Jenne, R., and Fiorino, M.: TheNCEP-NCAR 50year Reanalysis: Monthly Means CD-ROM and Documentation, B. Am. Meteorol. Soc., 82, 247-267, 2001.

Lionello, P., Malanbotte-Rizzoli, P., and Boscolo, R. (Eds.): Mediterranean Climate Variability, Developments in Earth and Environmental Sciences 4, Elsevier, pp. 325-372, 2006.

Maheras, P., Flocas, H., Patrikas, I., and Anagnostopoulou, Ch.: A 40 year objective climatology of surface cyclones in the Mediterranean region: spatial and temporal distribution, Int. J. Climatol., 21, 109-130, 2001.

Petterssen, S.: Weather Analysis and Forecasting, Vol I., McGrawHill, New York, 428, 1956.

Reiter, R.: Handbook For Forecasters in the Mediterranean, Paper No. 5-75, Naval Post-graduate school, Monterey, CA, 344 pp., 1975 .

Trewartha, G. T. and Horn, L. H.: An Introduction to Climate, Fifth edition, McGraw-Hill book company, N.Y, pp. 148-156, 1980.

Trigo, I. F, Davies, T. D., and Bigg, G. R.: Objective Climatology of Cyclones in the Mediterranean Region, J. Climate, 12, 6, 16851696, 1999.

Trigo, I. F.: Climatology and Interannual Variability of StormTracks in the Euro-Atlantic Sector: a Comparison between ERA40 and NCEP/NCAR Reanalysis, Clim. Dynam., 26(2-3), 127 143, 2006.

Ziv, B.: A subtropical rainstorm associated with a tropical plume over Africa and the Middle-East, Theor. Appl. Clim., 69, 1/2, 91-102, 2001. 